\title{
ALPHA-PINENE ATTENUATES MICROGLIAL NF-KB ACTIVATION AND INOS EXPRESSION IN GP120-INDUCED NEUROINFLAMMATION
}

\author{
Masruroh Rahayu ${ }^{1,2}$, M Aris Widodo $^{1}$, Diana Lyrawati ${ }^{1}$, Edi Widjajanto
}

Correspondence: masrurohrahayu@yahoo.co.id

${ }^{1}$ Post Graduate Study, Faculty of Medicine Universitas Brawijaya, Malang, Indonesia

${ }^{2}$ Neurology Department, Faculty of Medicine Universitas Brawijaya, Malang, Indonesia

\section{Article History: \\ Received: December 8, 2020 \\ Accepted: December 22, 2020 \\ Published: January 1, 2021 \\ Cite this as: Vancouver style Rahayu M, Widodo MA, Lyrawati $D$, Widjadjanto E. Alpha-pinene attenuates microglial $n f-\kappa b$ activation and inos expression in gp120-induced \\ neuroinflammation. Malang Neurology Journal; 2021.7:80- 84. \\ http://dx.doi.org/10.21776/ub.mnj 2021.007.01.16}

\section{ABSTRACT}

Background: Neuroinflammation plays a role in the pathogenesis of HIV-associated dementia (HIV). Activation of microglia is essential for triggering inflammatory-mediated neurotoxicity. HIV-1 120 $\mathrm{kDa}$ envelope glycoprotein (gp120) induces microglial NF- $\mathrm{KB}$ signaling which in turn induces proinflammatory and iNOS gene transcription. Continuous or excessive activation of NF- $\mathrm{\kappa B}$ signaling leads to persistent production of TNF- $\alpha$ and nitric oxide by microglia and induces neuronal apoptosis. Alpha-pinene is a natural substance extracted from a pine tree and has efficacy in inhibiting NF- $\mathrm{BB}$ signaling.

Objective: This study was designed as a true experimental study and aimed to investigate the effect of alpha-pinene administration toward inflammatory response represented by the percentage of microglia containing activated NF- $\mathrm{KB}$ and iNOS expression.

Methods: Neuron-glia primary culture from brain tissue of rat fetus was divided into 5 groups as follows: negative control; positive control (gp120 1nM); treatment I, II, and III (gp120 $1 \mathrm{nM}+$ alphapinene $0.4 \mu \mathrm{g} / \mathrm{mL}, 2 \mu \mathrm{g} / \mathrm{mL}$, and $10 \mu \mathrm{g} / \mathrm{mL}$, respectively). Microglial NF- $\kappa B$ and iNOS expression were analyzed using the immunohistochemistry method. Neuronal apoptosis was measured by the TUNNEL method.

Results: Results showed that alpha-pinene administration on gp120-treated neuron-glia at all dosages decrease NF-kB activation, iNOS expression, and apoptotic neuron significantly as compared to the gp120-only treated group $(\mathrm{p}<0.05)$. Furthermore, alpha-pinene did not affect NF-kB activation and neuronal apoptosis $(p>0.05)$, but significantly elevate iNOS expression $(p<0.05)$ mainly in dosage I and II.

Conclusion: We concluded that alpha-pinene has neuroprotective effect on gp120-treated neuron-glia cells through modulation of NF-kB and iNOS expression thus inhibit neuronal apoptosis.

Keywords: apoptosis, gp120, iNOS, neuroinflammation, NF-kB

\section{Introduction}

Human Immunodeficiency Virus -1 (HIV-1)-associated dementia (HAD) is subacute or chronic dementia characterized by impairment of neurocognitive, motoric, and behavior. Those symptoms result from neuronal death associated with HIV-1 infection in the central nervous system. ${ }^{1,2,3}$

Human Immunodeficiency Virus -1 (HIV-1)-associated dementia (HAD) is accounted for approximately $20 \%$ of HIV-1-infected patients. ${ }^{4}$ It has been postulated that neuroinflammation plays a role in the pathogenesis of the neurodegenerative disease, including HAD. ${ }^{2,5}$ Even in a patient treated with highly active antiretroviral therapy (HAART), HAD still occurred, because HAART is only focused on reducing systemic viral load, but not targeting the neuroinflammation process. ${ }^{3}$ Therefore, it is required to administrate additional treatment to modulate the progressivity of HAD.
The population of brain cells consists mainly of the neuron and glial cells (microglia and astrocyte). Microglia play an essential role in the defense mechanism in the central nervous system and vulnerable to relatively slight physiological changes. Activated microglia have the same characteristics as a macrophage which is indicated by rapid proliferation, cytotoxic compound secretion, phagocytosis, and antigen presentation.

Activation of microglia is initiated by binding of gp120 into its receptor, CD4, and its co-receptor, CXCR4 (or CCR5) on the microglia's cell membrane. This binding will induce mitogen-activated protein kinases (MAPK) signaling $^{6}$ indicated by activation of c-Jun N-terminal kinase (JNK) and $\mathrm{p} 38$, and then sequentially activate transcription factor nuclear factor kappa B $(\mathrm{NF}-\mathrm{KB})$. Induction of $\mathrm{NF}-\mathrm{\kappa B}$ triggers upregulation and secretion of proinflammatory cytokines, TNF- $\alpha$, and IL- $1 \beta^{7,8}$, thus consequently lead to neurotoxic reactive oxygen species (ROS) production. ${ }^{9}$ Interestingly, TNF- $\alpha$ and ROS could activate NF-KB ${ }^{10,11,12}$, so there will be excessive TNF- $\alpha$ stimulation. Furthermore, 
excessive TNF- $\alpha$ will induce apoptotic pathway through the activation of caspase. ${ }^{10}$

Transcription factor nuclear factor- $\kappa \mathrm{B}(\mathrm{NF}-\kappa \mathrm{B})$ is a critical mediator in neurodegenerative disorders include HAD and plays a role in the regulation of proinflammatory response. Several genes regulated by NF- $\kappa \mathrm{B}$ are iNOS, cytokines, chemokines, adhesion molecules, and immune receptors. In a physiologic state, $N F-\kappa B$ activation is designed for the beneficial defense mechanism of neuronal cells in critical condition. However, excessive and continuous activation of this pathway will jeopardize the survival of neuronal cells and brain tissue. ${ }^{13}$

Activated microglia also produces and secretes nitric oxide (NO) that is formed through inducible nitric oxide synthase-mediated reaction, and NO formation could induce neuronal apoptosis. ${ }^{14,15}$ The amplification of NF- $\mathrm{NB}$ activation could multiply proinflammatory, and NO signaling thus induces apoptosis of neurons. Developing neuroprotective drugs targeting $\mathrm{NF}-\kappa \mathrm{B}$ signaling is potential because it could inhibit several pathways involved in neuronal apoptosis.

Essential oil and terpenoid which have anti-inflammatory properties could be used as phytotherapy. ${ }^{16,17}$ The main constituent of essential oil and terpenoid extracted from the pine tree is alpha-pinene. Alpha-pinene $(\mathrm{C} 10 \mathrm{H} 16)$ is a nonpolar (hydrophobic) compound with molecular weight $136.24 \mathrm{~g} / \mathrm{mol}$, present in liquid form, and volatile. ${ }^{18}$ The volatile characteristic of alpha-pinene has a beneficial effect on its utilization for inhalation therapy in a particular case such as behavior disorders include dementia patients. ${ }^{19}$

Studies of neuroinflammation are commonly used lipopolysaccharide for the induction of inflammation. In this study, we used HIV-1 glycoprotein 120 (gp120) for inducing inflammation response in the model of HIV-1related neurodegeneration in vitro. ${ }^{20}$ This study was aimed to investigate the effect of alpha-pinene administration on the expression of microglia's activated NF- $\mathrm{BB}$, iNOS, and neuronal apoptosis.

\section{Methods}

\section{Study Design}

This study was designed as a true experimental study using primary cell culture of fetal rat neuron-glia which was divided into eight groups as follow: negative control; positive control (gp120 1 nM); alpha-pinene only dose I, II, and III $(0.4 \mu \mathrm{g} / \mathrm{ml}, 2 \mu \mathrm{g} / \mathrm{ml}$, and $10 \mu \mathrm{g} / \mathrm{ml}$, respectively); gp120 + alpha-pinene dose I, II, and III $(0.4 \mu \mathrm{g} / \mathrm{ml}, 2$ $\mu \mathrm{g} / \mathrm{ml}$, and $10 \mu \mathrm{g} / \mathrm{ml}$, respectively). This study was done in the Biomedical Laboratory, Faculty of Medicine, Universitas Brawijaya. In a gp120-treated group, gp120 $1 \mathrm{nM}$ was administered 1 hour before treatment of alphapinene with three dosages.

\section{Primary Culture of Rat Fetal Neuron-Glia}

The procedures of fetal brain tissue isolation and primary culture of fetal rat neuron-glia were performed as described previously in the literature. ${ }^{21}$ Briefly, pregnant rats at gestation day 16-17 were euthanized by cervical dislocation. Rats were laid on the back, and the abdominal area was cleaned with $70 \%$ ethanol. By surgical procedure, the fetus was taken from the uterus. Fetuses were laid on a petri dish containing sterile phosphate buffer saline (PBS) and then carried to the biological safety cabinet under laminar airflow. The head of a fetus was wiped with $70 \%$ ethanol and euthanized by decapitation. The fetal brain was rinsed with PBS Penstrep, incised and then fetal brain tissue was removed. Fetal brain tissue was separated from the meninges, and red blood cells were then washed again with PBS Penstrep. The brain tissue was then transferred into four microtubes which each microtube was added with 400 $\mu 1$ Trypsin EDTA. Brain tissue then will be incubated in $\mathrm{CO}_{2} 5 \%$ incubator with temperature $37^{\circ} \mathrm{C}$ for 15 minutes. After this process, each microtube was added with $600 \mu 1$ fetal bovine serum (FBS) $10 \%$ in PBS, then centrifuged at $1200 \mathrm{rpm}$, room temperature, for 2 minutes. The supernatant was removed, and the pellet was added with $800 \mu \mathrm{l} \mathrm{FBS} 10 \%$ in PBS for each microtube, centrifuged again at $1200 \mathrm{rpm}$, room temperature, for 2 minutes. After this process, the supernatant was removed, then the pellet was added again with $800 \mu \mathrm{l}$ serum-free media for each microtube, centrifuged again at $1200 \mathrm{rpm}$, room temperature, for 2 minutes. The supernatant was removed, and the pellet was added with complete media until reach $1.5 \mathrm{~mL}$ volume, and then pipetted carefully. Cells were cultured on well-12, each well contains $450 \mu \mathrm{l}$ and then added with $500 \mu \mathrm{l}$ complete media, incubated in $\mathrm{CO}_{2} 5 \%$ with temperature $37^{0} \mathrm{C}{ }^{21}$

\section{Measurement of NF-kB and iNOS Expression}

Measurement of NF-kB and iNOS expression were performed using an immunocytochemistry kit as instructed by the manufacturer.

\section{Measurement of Apoptosis}

Detection of apoptosis was done using a TUNEL assay kit as instructed by the manufacturer.

\section{Statistical Analysis}

Data were analyzed using software SPSS version 17.0. Statistical analysis using in this study consist of independent T-test, One-way ANOVA, and correlation study. Data were analyzed using a confidence interval of $95 \%$ and assumed as significant of $\mathrm{p}$-value $<0.05$.

\section{Results}

\section{Effect of Alpha Pinene on NF-kB Activation}

This study showed that alpha-pinene administration decrease the percentage of microglia containing activated NF-kB in gp120-treated neuron-glia (mean $37.02 \pm 18.55 \%$, $33.19 \pm 2.82 \%$, and $32.69 \pm 6.44 \%$ at the dose I, II, and III, respectively vs. $57.57 \pm 15,20 \%$ at the gp120-only group) (One Way ANOVA, p<0.05). Furthermore, alpha-pinene administration at all dosages increases activation of NF-kB in neuron-glia culture insignificantly as compared to the negative control group (Figure 1). All figures, tables, or informative illustrations are prepared as an HD image file.

Visualization of activated microglia is characterized by its processes. Microglia containing inactivated NF- $\kappa \mathrm{B}$ demonstrates a blue nucleus as shown in Figure 2(1), while microglia containing activated $\mathrm{NF}-\kappa \mathrm{B}$ demonstrates dark cytoplasm and nucleus as shown in Figure 2. 


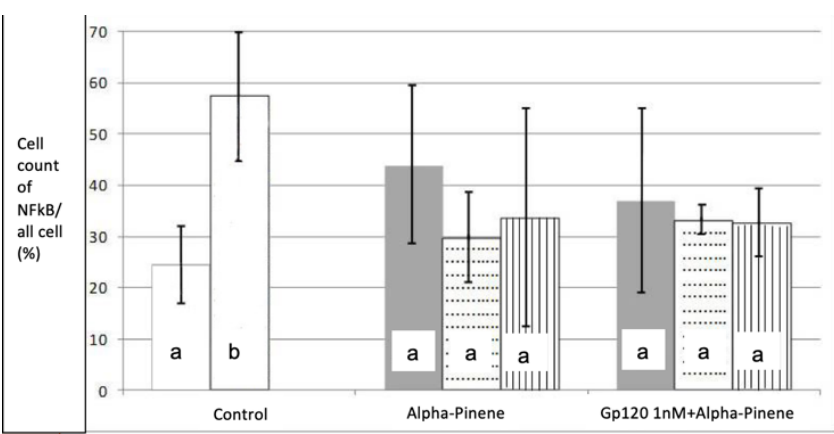

Figure 1. Percentage of microglia containing activated NF- $\kappa \mathrm{B}$ in each group.

Note: (a) Negative control; (b) Positive control (gp120 1nM); (c) alpha-pinene I 0,4 ug/mL; (d) alpha-pinene II 2,0 ug/mL; (e) alpha-pinene III $10 \mathrm{ug} / \mathrm{mL}$; (f) gp120 1nM + alpha-pinene I 0,4 ug/mL; (g) gp120 1nM + alpha-pinene II 2,0 ug/mL; (h) gp120 $1 \mathrm{nM}+$ alpha-pinene III $10 \mathrm{ug} / \mathrm{mL}$; Same notation indicates no significant differences and vice versa.
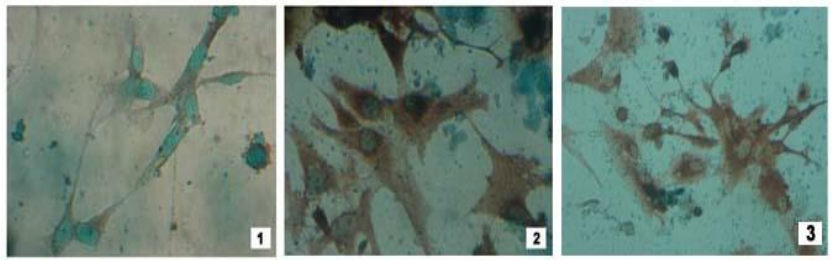

Figure 2. Microglia containing inactivated and activated NF- $\kappa B$ Note: (1) negative control: rat brain neuron-glia culture without any treatment, (2) GP-120 treated neuron-glia culture, the figure demonstrates microglia containing activated NF- $\mathrm{KB}$ as indicated

by dark nucleus as compared to control caused by NF- $\kappa \mathrm{B}$ translocation into the nucleus, (3) neuron-glia culture treated with GP-120 + alpha-pinene $10 \mathrm{ug} / \mathrm{mL}$. (Inverted microscope, Olympus, magnitude 400x)

\section{Effect of Alpha Pinene on iNOS Expression}

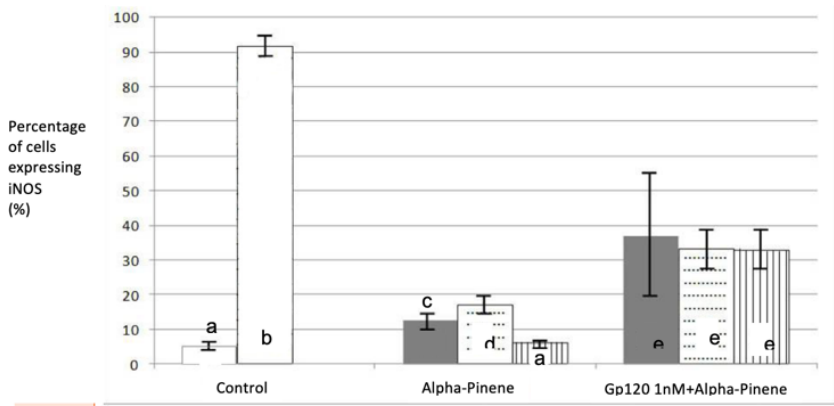

Figure 3. Percentage of microglia expressing iNOS.

Note: (a) Negative control; (b) Positive control (gp120 1nM); (c) alpha-pinene I 0,4 ug/mL; (d) alpha-pinene II 2,0 ug/mL; (e) alpha-pinene III $10 \mathrm{ug} / \mathrm{mL}$; (f) gp120 1nM + alpha-pinene I 0,4 $\mathrm{ug} / \mathrm{mL} ;(\mathrm{g})$ gp120 1nM + alpha-pinene II 2,0 ug/mL; (h) gp120 $1 \mathrm{nM}+$ alpha-pinene III $10 \mathrm{ug} / \mathrm{mL}$; Same notation indicates no significant differences and vice versa.

This study showed that alpha-pinene administration decrease the percentage of microglia expressing iNOS in gp120-treated neuron-glia (mean 38.52 $\pm 28.3 \%$, $27.67 \pm 1.98 \%$, and $56.78 \pm 3.42 \%$ at the dose I, II, and III, respectively vs. $91.76 \pm 2.97 \%$ in the gp120-only group) (One Way ANOVA, p<0.05) (Figure 3). Furthermore, alpha-pinene administration at all dosage increase expression of NF-kB in neuron-glia culture significantly as compared to the negative control group but significantly lower as compared to the gp-120 + alpha-pinene group (Figure 3). Figure 4 showed normal microglia ${ }^{1}$, while microglia expressing iNOS indicated by red cytoplasm.

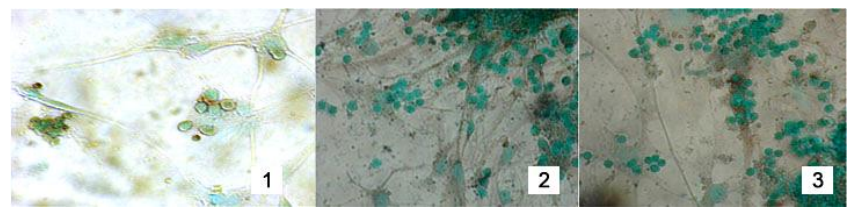

Figure 4. Microglia normal and highly expressing iNOS.

Note: (1) negative control: neuron-glia culture without any treatment, (2) gp120-treated neuron-glia (3) neuron-glia treated with gp120 + alpha-pinene $10 \mathrm{ug} / \mathrm{mL}$. Microglia expressing iNOS is indicated by dark cytoplasm (bold arrow). Microglia without iNOS expression is indicated by light cytoplasm (light arrow). (Inverted microscope, Olympus, magnitude 100x.

\section{Effect of Alpha Pinene on Neuronal Apoptosis}

This study showed that alpha pinene administration decrease the percentage of apoptotic neuron in gp120treated neuron-glia (mean $21.77 \pm 4.41 \%, 8.07 \pm 4, .34 \%$, and $17.77 \pm 13.59 \%$ at the dose I, II, and III, respectively vs $63.49 \pm 1.76 \%$ in gp120-only group) (One Way ANOVA, $\mathrm{p}<0.05$ ) (Figure 5). Furthermore, alpha-pinene dose 2.0 decrease apoptotic neuron significantly as compared to the lowest dose in the gp120-treated group $(8.07 \pm 4.34 \%$ vs $21.77 \pm 4.41 \% ; \mathrm{p}<0,05)$.

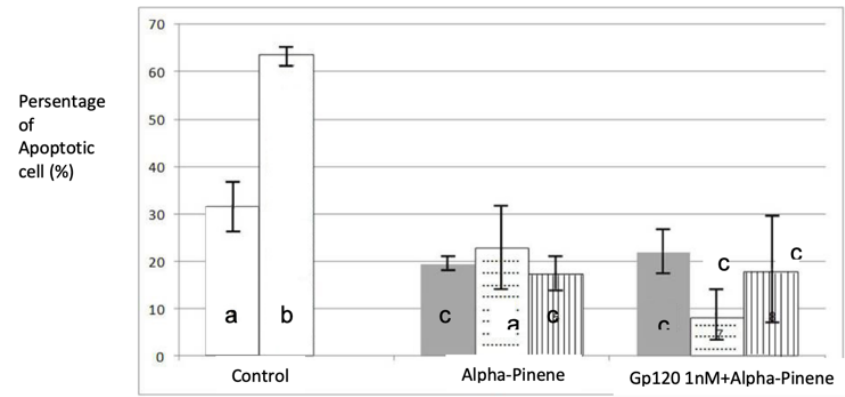

Figure 5. Percentage of microglia contained apoptotic neuron Note: (a) Negative control; (b) Positive control (gp120 1nM); (c) alpha-pinene I 0,4 ug/mL; (d) alpha-pinene II 2,0 ug/mL; (e) alpha-pinene III $10 \mathrm{ug} / \mathrm{mL}$; (f) gp120 1nM + alpha-pinene I 0,4 ug/mL; (g) gp120 1nM + alpha-pinene II 2,0 ug/mL; (h) gp120 $1 \mathrm{nM}+$ alpha-pinene III $10 \mathrm{ug} / \mathrm{mL}$; Same notation indicates no significant differences and vice versa.
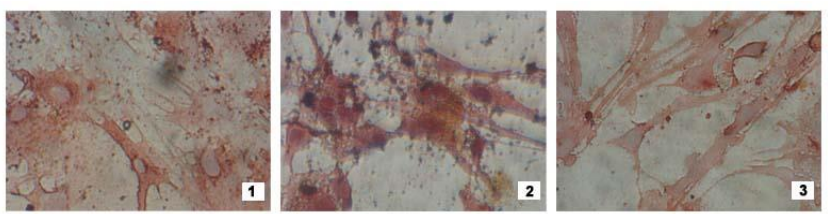

Note: (1) Negative control; (2) Positive control (gp120 1nM); (3) alpha-pinene II 2,0 ug/mL. Black arrow showed apoptotic cell with brown nucleus. (Inverted microscope, Olympus, 400x)

\section{Discussion}

In this study, alpha-pinene did not affect the number of microglia containing NF- $\mathrm{BB}$ in untreated neuron-glia, but alpha pinene could reduce the number of microglia containing NF- $\kappa \mathrm{B}$ in gp120-treated neuron-glia. This 
finding suggested that alpha pinene could selectively alter the neuron-glia cells in an inflammatory state and did not affect healthy cells.

Exposure of gp120 will increase its binding to the CD4 receptor and chemokines receptor (CCX4 and CXCR-5). This binding activates the signaling pathway for the activation of protein kinase $\mathrm{MAPK}^{22}$, which in turn leads to IkB degradation and release of $N F-\kappa B$. Activated NF- $\mathrm{NB}$ translocates to the nucleus and binds to specific DNA thus induces the transcription process of several proinflammatory genes as well as Inos. ${ }^{23}$

This study demonstrated that alpha pinene administration to gp120-treated neuron-glia decreases the number of microglia expressing iNOS. iNOS has been known as a catalyst for nitric oxide (NO) formation. ${ }^{24}$ As alpha pinene decreases NO production, it could be used as antiinflammatory agents particularly in gp120-induced neuroinflammation.

Alpha-pinene is contained in essential oil chamomile and has been used for a century for its anti-inflammatory properties in the treatment of eczema, dermatitis, and irritation. $^{25}$ Chemical analysis on essential oil from $\mathrm{J}$. Oxycedrus has been reported, and it showed that one fraction from essential oil which contains $93 \%$ alpha pinene could induce IkB degradation and activates NF- $\mathrm{kB}$. A previous study using chondrocyte cell line C-28/I2 demonstrated that alpha pinene reduces $\mathrm{IkB}$ phosphorylation thereby reduce the activation of $\mathrm{NF}-\kappa \mathrm{B}$ and its DNA binding activity. ${ }^{26}$

These studies confirm the role of alpha-pinene as antiinflammatory agents mainly through its modulation of NF$\kappa \mathrm{B}$ signaling. However, further study is required for investigating the effect of alpha-pinene especially for the treatment of neuroinflammation mediated neurodegenerative disease, including HAD.

Our study also showed that alpha pinene decreases the expression of iNOS in gp120-treated neuron-glia significantly in all dosages of alpha-pinene as compared to the gp120-treated group. This result was in accordance with the previous study reported that alpha pinene administration dosage $2,0 \mathrm{ug} / \mathrm{mL}$ and $0,4 \mu \mathrm{g} / \mathrm{mL}$ inhibit iNOS expression in LPS-treated neuron-glia. ${ }^{27}$ Together with this result, we could hypothesize that alpha pinene administration could be beneficial in several situations highlighted by neuroinflammation such as HAD and other neurodegenerative disorders such as Parkinson disease and Alzheimer disease.

Further experiment showed that alpha pinene dosage 10 $\mathrm{ug} / \mathrm{mL}$ for 24-hour decrease the number of apoptotic neuron in untreated neuron-glia culture. On the other hand, the previous study showed that alpha pinene administration (dosage $10 \mathrm{ug} / \mathrm{mL}$ and $100 \mathrm{ug} / \mathrm{mL}$ for 2 hours) induces neuronal apoptosis in neuron-glia culture. ${ }^{28}$ From these studies, we could say that the dosage of alpha-pinene is correlated with pharmacological activity. Low dose alphapinene $(10 \mathrm{ug} / \mathrm{mL})$ has a dual effect, neuroprotective and neurotoxic, while high dose alpha-pinene $(100 \mathrm{ug} / \mathrm{mL})$ possesses a neurotoxic effect. Considering the duration of treatment, acute treatment ( 2 hours) with low dose alpha pinene has a neurotoxic effect, while low dose administration in 24 hours has a neuroprotective effect.

\section{Conclusion}

We concluded that alpha pinene has a potential role in inhibiting neuroinflammation mediated by gp120 as indicated by NF-kB expression, iNOS expression, and also neuronal apoptosis.

\section{Acknowledgement}

None

\section{References}

1. Heaton RK, Franklin DR, Ellis RJ, et al. HIVassociated neurocognitive disorders before and during the era of combination antiretroviral therapy: differences in rates, nature, and predictors. $\mathrm{J}$. Neurovirol; 2011. 17:3-16. DOI: 10.1007/s13365010-0006-1

2. Block ML, Zecca L, Hong JS. Microglia-mediated neurotoxicity: Uncovering the molecular mechanisms. Nat. Rev. Neurosci; 2007. 8 : 57-69. Avalaible from: https://www.nature.com/articles/nrn2038

3. Ghafouri M, Amini S, Khalili K and Sawaya BF. HIV-1 associated dementia: symptoms and causes. Retrovirol; 2006. 3:28-35. DOI: 10.1186/1742-46903-28

4. Yadav A, Collman RG. CNS Inflammation and macrophage/microglial biology associated with HIV-1 infection. J Neuroimmune Pharmacol; 2009. 4:430447. DOI: $10.1007 / \mathrm{s} 11481-009-9174-2$

5. Gao M and Hong JS. Why neurodegenerative diseases are progressive: Uncontrolled inflammation drives disease progression. Trends Immunol; 2008. 29(8): 357-365. DOI: 10.1016/j.it.2008.05.002

6. Medders KE, Sejbuk NE, Maung R, et al. Activation of p38 MAPK is required in monocytic and neuronal cells for HIV glycoprotein 120-induced neurotoxicity. J Immunol; 2010. 185:4883-4895. DOI: $10.4049 /$ jimmunol.0902535

7. Rumbaugh JA, and Nath A. Developments in HIV neuropathogenesis. Current Pharmaceutical Design; 2006. 12:1023-1044.

8. Brabers NACH and Nottet HSLM. Role of the proinflammatory cytokines TNF-a and IL-1 $\beta$ in HIVassociated dementia. European Journal of Clinical Investigation; 2006. 36: 447-458.

DOI: $10.1111 / \mathrm{j} .1365-2362.2006 .01657 . x$

9. Dheen ST, Kaur C, Ling E. Microglial activation and its implications in the brain diseases. Current Medicinal Chemistry; 2007. 14:1189-1197. DOI:

10. Herbein G, Gras G, Khan KA, et al. Macrophage signaling in HIV-1 infection. Retrovirology; 2010. 7: 1-13. Avalaible from:

https://retrovirology.biomedcentral.com/articles/10.11 86/1742-4690-7-34

11. Pande V and Ramos MJ. NF-кB in human disease: current inhibitors and prospect for de novo structure based design of inhibitors. Current Medicinal Chemistry; 2005. 12:357-374. DOI: $10.2174 / 0929867053363180$

12. Qin Z, Tao L, Chen X. Dual roles of NF-kB in cell survival and implications of NF-kB inhibitors in 
neuroprotective therapy. Acta Pharmacol Sin; 2007. 28 (12): 1859-1872. Avalaible from: https://www.nature.com/articles/aps2007228

13. Heras B and Hortelano S. Molecular basis of the antiinflammatory effects of terpenoids. Inflammation \& Allergy - Drug Targets; 2009. 8: 28-39 . DOI: $10.2174 / 187152809787582534$

14. Kalinichenko SG and Matveeva. Morphological Characteristics of Apoptosis and Its Significance in Neurogenesis. Neuroscience and Behavioral Phys 2008; 38(4): 333-344. DOI: 10.1007/s11055-0080046-7.

15. Polazzi E and Monti B. Microglia and neuroprotection: From in vitro studies to therapeutic applications. Progress in Neurobiology; 2010. 92: 293-315. DOI: 10.1016/j.pneurobio.2010.06.009

16. Mercier B, Prost J, Prost M. The essential oil of turpentine and its major volatile fraction $(\alpha-$ and $\beta$ pinenes): A review. Journal of Occupational Medicine and Environmental Health; 2009. 22(4):331 - 342. DOI: $10.2478 / \mathrm{v} 10001-009-0032-5$

17. Salminen A, Lehtonen $M$, Suuronen $T$ et al. Terpenoids: Natural inhibitors of NF- $\kappa \mathrm{B}$ signaling with anti-inflammatory and anticancer potential. Cell Mol.Life Sci; 2008. 65:2979-2999.

DOI: $10.1007 / \mathrm{s} 00018-008-8103-5$

18. Lin CT, Chen CJ, Lin TY et al. Anti-inflammation activity of fruit essenstial oil from cinnamomum insularimontanum hayata. Bioresour Technol; 2008. 18:8783-8787. DOI: 10.1016/j.biortech.2008.04.041

19. Holt FE, Birks TPH, Thorgrimsen LM, Spector AE. et al. Aromatherapy in dementia. The Cochrane Collaboration, Joh Wiley \& Sons; 2009. pp. 1-10.

20. Nesbit CE and Schwartz SA. In vitro and animal models of human immunodeficiency virus infection of the central nervous system. Clin and Diagnostic Lab Immunol; 2002. 9(3): 515-524. DOI: 10.1128/CDLI.9.3.515-524.2002
21. Jana M, Jana A, Pal U. et al. A simplified method for isolating neuron, oligodendrocytes, astrocytes and microglia from the same human fetal brain tissue. Neurochem Res; 2007. 32(12):2015-2022. DOI: 10.1007/s11064-007-9340-y

22. Kanmogne GD, Schall K, Leibhart J. et al. HIV-1 gp120 compromises blood barrier integrity and enhance monocyte migration across blood-brain barrier: Implication for viral neuropathogenesis. J.Cereb Blood Flow \& Metab; 2007. 27(1):123-134. DOI: DOI: $10.1038 /$ sj.jcbfm.9600330

23. Ivanenkov YA, Balakin KV, and Tkachenko SE. New approaches to the treatment of inflammatory disease. Drugs RD; 2008. 9(6):397-434.

DOI: 10.2165/0126839-200809060-00005

24. Saha $\mathrm{R}$ and Pahan K. Regulation of inducible nitric oxide synthase gene in glial cells. Antioxidants and Redox Signaling; 2006. 8(5): 929 -947. DOI: 10.1089/ars.2006.8.929

25. Miguel MG. Antioxidant and anti-inflammatory activities of essenial oils: A short review. Molecules; 2010. 15: 9252-9287. DOI: 10.3390/molecules 15129252

26. Neves A, Rosa S, Goncalves J, et al. Screening of five essential oils for identification of potential inhibitors of il-1-induced nf- $\mathrm{kb}$ activation and no production in human chondrocytes: Characterization of the inhibitory activity of alpha-pinene. Planta Med; 2010. 76: 303-308. DOI: 10.1055/s-0029-1186085

27. Murtyastami K. Kajian efek alfa-pinen terhadap inos pada kultur sel neuron-glia yang dipapar lipopolisakarida [Skripsi]. Jurusan Biologi Fakultas MIPA, Universitas Brawijaya, Malang; 2008.

28. Jayanti GE. Peranan alpha-pinene terhadap apoptosis neuron [Tesis]. Pascasarjana Universitas Brawijaya Malang; 2010. 